\title{
DYNAMICS OF STUDENTS' PSYCHOLOGICAL AND EMOTIONAL STATES IN DANCE MOVEMENT TRAINING
}

\author{
Alexander V. Gutko \\ Lobachevsky State University of Nizhni Novgorod, Russia \\ Elena N. Letiagina \\ Lobachevsky State University of Nizhni Novgorod, Russia \\ Elena A. Orlova \\ Lobachevsky State University of Nizhni Novgorod, Russia
}

Olga V. Suvorova

Minin Nizhny Novgorod State Pedagogical University, Russia

Larisa N. Kuzminykh

Minin Nizhny Novgorod State Pedagogical University, Russia

\begin{abstract}
The article presents a study of the dynamics of students' psychological and emotional state in the implementation of the author's program of dance movement training. The effectiveness of the training was monitored by evaluating the types of the participants' psychological problems and their emotional and functional state.

The study involved 96 students of Nizhny Novgorod universities aged from 18 to 25 . We used: the author's questionnaire for subjective evaluation of the training participants' psychological problems; Cattell's questionnaire; the method of computer campimetry to assess the functional state of the body by the function of color differentiation. The technology used for measuring differential thresholds based on the coordinates of color models in a computer environment was the HandTracker (Polevaya) campimetry test for virtual environment. The system of dance movement training included methods of body-oriented psychotherapy, vegetotherapy, dance movement therapy, including contact improvisation. The structure of the class included: warm-up (aerobic and anaerobic exercise, muscle stretching exercises);
\end{abstract}


thematic muscle relaxation; choreographic performances (learning movement stereotypes, free and contact improvisation).

The data of the control experiment show statistically significant dynamics of the main indicators of psychological and emotional states $(P<0.05)$. At the same time, the dynamics of anxiety is statistically significant, while the level of depression decreased only at the trend level.

Keywords: dance movement therapy, psychological and emotional states, students, functional states.

\section{Introduction}

Dance movement therapy is a positive and emotionally intense motor experience widely used in modern psychological and educational practice.

Dance movement therapy is popular because the mechanisms of its influence on psycho-physical health and personal growth are obvious and well-studied (Rohricht, 2009; Earhart, 2009; Julian, Cherkin, Steuten, Sherman, Vrijhoef, 2011; Karkou, Meekums, 2017; Pallaro, 2007, etc.).

The uniqueness of the impact of dance movement therapy is in the integrative influence on the subject's psychophysical individuality as a whole (Hannah, 2007; Levi, 1988). At the same time, the researchers state the lack of validity of the effects of dance movement therapy, which is due to small samples and low quality of quantitative data, as well as the insufficient duration of studies (Erhart 2009), which reduces the external validity of the results.

Nevertheless, the results of studies of the influence of dance movement therapy on the psycho-emotional state in neurological and psychosomatic diseases (Erhart, 2009; Karkou, Meekum, 2017) allow us to assume the effectiveness of the use of dance motor therapy as a positive activity in order to prevent psycho-emotional problems in students.

The relevance of our study is due to a sufficiently large sample of respondents and the use of sustainable contact groups of DDT. In this article, we present the data on the study of the influence of dance movement therapy on the psychological and emotional state of students participating in the training group.

Stable psychological and emotional states (states of satisfaction/ dissatisfaction, stable functional states) at student age most often reflect the effectiveness of solving the key problems of this age: academic and social success, interpersonal and intimate relationships. The problem of dissatisfaction with one's own image of the body is quite acute, especially in girls, from the perspective of solving the latter issues. Studies show that body image in case of college and university students is related to satisfaction with oneself (Blanco, Rivera, Gonzalez, Rodriguez-Villalobos, 2015; 
Wright, 2012); academic performance and self-efficacy (Newton, 2015); self-esteem (Daniali, Azadbakht, Mostafavi, 2013); the type of preferred physical activity, attitude of family and friends (Pop, 2016; Holmqvist Gattario, 2013); one's life habits (Lowery, 2005).

Dissatisfaction with oneself and one's body reduces self-acceptance and causes a state of frustration, anxiety, social maladjustment, and makes communication difficult (Reich, 1999; Lowen, 2002; Shilder, 1978).

The answer to the problem of students' dissatisfaction with themselves is, first of all, positive motor activity with the experience of pleasure and joy (Gattario Holmquist, 2013). Dance movement therapy is a communicative and emotionally intense motor and physical practice that enhances self-acceptance, gives emotional relaxation/catharsis through creative selfexpression and arouses great interest among students.

\section{Methodology}

We believe that the system of dance movement training is an effective practice of emotional relaxation and optimization of mental states of students.

The aim of this study was to study the dynamics of emotional and functional states of students - dance-motor training participants.

We used the author's questionnaire for subjective assessment of the participants' psychological problems; Cattell's questionnaire; the method of computer campimetry to assess the functional state of the body according to the color differentiation function (Polevaya, Runova, Nekrasova, 2012). Statistical assessment of the dynamics was carried out using the $\chi^{2}-$ Pearson test and Student's t-test.

The system of dance movement training took place at the Studio of dance movement improvisation "Kinesio" (Nizhny Novgorod) under the direction of L.N. Kuzminykh. The study involved 96 students of Nizhny Novgorod universities and colleges, including 58 women and 38 men aged 18 to 25 who visited the Studio during the year. The control group included 84 students, 49 women and 35 men aged 18 to 25 .

The respondents of the experimental group attended classes in the Studio on their own initiative. The selection of respondents for the control group was based on university students' voluntary participation in the survey; the sample of subjects in the control group was formed by random number generation.

The objectives included: to study the psychological and emotional problems of the group members; to measure differential color discrimination thresholds as indicators of the functional state; to develop a program of group dance and motor training, including group psychotherapeutic classes 
on motor improvisation and expressive plastics based on images of world art culture; to conduct a control experiment.

\section{Results}

The survey has revealed a range of students' psychological problems. The authors' questionnaire for the subjective assessment of participants' psychological problems included a list of typical social and personal problems, and students were asked to choose personal life problems from the proposed list. The frequency of students' responses indicating problems of interpersonal relationships, self-confidence and the need for selfexpression, psycho-emotional states and moods, etc., was calculated.

In this study, we used the classic Cattell's questionnaire as adapted by V. I. Pokhilko, A.S. Soloveichik and A.G. Shmelev (Mst = 5.5; st = 2). An analysis was performed of the group mean profile values that significantly deviated from the normative profile.

Campimetry (lat. campus - field + gr. metreo - measure) is a group of methods for the investigation of the central and paracentral parts of the visual field on a computer screen. Computer campimetry is a technology for measuring differential thresholds by the coordinates of color models in a virtual computer environment (Bakhchina, Koroleva, Polevaya, 2015). Campimetry is used for a qualitative and quantitative evaluation of the degree of damage of visual functions in medicine and in physiology (Bakhchina, Koroleva, Polevaya, 2015). In psychophysiology, campimetry is widely used to assess functional mental states through the study of maximum thresholds of color differentiation (Stromkova, Parin, Polevaya, 2004).

We used the maximum differential thresholds for color differentiation by basic colors (green, blue, red) as indicators of the respondents' mental states. In this study, the campimetry test in the HandTracker virtual environment (Bakhchina, Koroleva, Polevaya, 2015) was used to measure color discrimination thresholds. In this test, a set of color stimuli generated inside the virtual color model is proposed. The set of stimuli includes 25 color samples (5 basic colors, with 5 shades of each), which are presented to the subject in a random order. Each stimulus consists of a color background (background stimulus) and a color figure (target stimulus) inside the background. At the initial presentation of each stimulus to the subject, the values of the background shades and the target stimulus shades are equal. The subject's task is to determine the shape of the target stimulus in the background, by increasing the value of its shade in relation to the background shade. Each subject's differential thresholds are then measured on a scale and a base color with the maximum differential threshold is 
chosen. Next, the percentage of subjects with the maximum differential threshold in a certain color (green, red, blue) is calculated.

Studies have demonstrated that measurements of the maximum differential threshold for color discrimination in a post-stress situation show a decrease in differential thresholds for color discrimination in green and an increase in blue and red. In the process of functional and stress loading, the maximum thresholds of color differentiation increase in the blue spectrum, while depressive states increase the maximum thresholds for color discrimination in the red spectrum (Stromkova, Parin, Polevaya, 2004; Polevaya, 2009).

A survey of respondents in the ascertaining experiment allowed us to identify some common psychological and emotional problems of the training group participants. Three quarters of the students indicated: inability to build deep interpersonal relations (78.12\%), psycho-emotional instability with a predominance of negative mood $(68.75 \%)$, dissatisfaction with one's own way of life in general (81.25\%), lack of a meaningful type of creativity, the need for creative self-expression $(85.41 \%)$; about half of the respondents indicated lack of self-confidence $(58.33 \%)$ and a high proneness to conflict (48.95\%).

Cattell's questionnaire showed that, in general, there was a prevalence of average ratings among the respondents for most personality factors in the sten score range from 6 to 7, the profile was quite uniform. At the same time, there was a tendency to affectothymia / factor A ( $M=7.56)$; sensitivity, capacity for empathy and understanding the other / factor I was decreased $(\mathrm{M}=3.27)$; there was also a pronounced tendency to hyperthymia, i.e. carelessness and self-confidence / factor $O(M=3.15)$.

The campimetric study showed the following ratio of subgroups of respondents: $22.91 \%$ tend to be depressed (with the maximum threshold in red); $15.62 \%$ show the state of anxiety (with the maximum threshold in blue); $61.47 \%$ have the optimal state (with the maximum threshold in green).

Thus, the ascertaining experiment revealed the markers of social maladaptation, psycho-emotional tension, anxiety, depression, increased reactivity, affectivity and sensitivity in the respondents.

Dance movement trainings with participants of the experimental group were conducted during one year (Gutko, Kuzminykh, Suvorova, 2018).

The following tasks were set: to encourage self-analysis, to analyze one's psychosomatic states, internal and external conflicts; to develop awareness of the relationship of the psyche, movements and bodily reactions in situations of spontaneous interaction, of the internal and external boundaries of one's body; to develop flexibility and to expand the range and variability of mental and motor reactions in situations of 
spontaneous interaction; to develop the skill, delicacy and complexity of self-presentation, spontaneity and arbitrariness; to develop the ability of awareness, evaluation and creative response to external changes.

Trainings were based on the methods of body-oriented psychotherapy, V. Reich's vegetotherapy, dance movement therapy, including contact improvisation.

The following techniques were used: sharing (verbalization of psychological and psychosomatic problems and states); warm-up using soft muscle stretching techniques; spontaneous dance based on an arbitrary image; contact improvisation with the learning of the basic skills of pair dance; choreography (thematic performance).

Each class included the following stages: warm-up (aerobic and anaerobic exercise, muscle stretching exercises), thematic muscle relaxation; choreographic performances with different forms and types of movements.

After studying new stereotypes of movements, a number of creative tasks for free improvisation in pairs and solos were given, work with one's voice and breath, as well as creative tasks for improvisation and verbal vocalization were offered. There was also a discussion of emotional states during the classes, which allowed the participants to identify unconscious resistance to new experiences, to clarify bodily experiences and feelings, as well as bodily response to new experiences.

The process of individual plastic creative performance smoothly turned into a contact improvisation by pairs and groups, where the skills of "recognition" and acceptance of another person and of building communication based on empathy were practiced.

Of special significance in trainings was the use of the works of world art culture and expressive plastics, as well as the use of the stress component, namely, plastic drama theatrical performances.

The following means of world art culture were used: listening to classical music, jazz and ethnic music with subsequent discussion; viewing and discussion of classical and modern paintings with the subsequent use of images in improvisational plastic performance; motor improvisation to poetry recited without music (Gutko, Kuzminykh, Suvorova, 2018). 
Table 1. Stages of implementation of the author's program of dance movement therapy training

\begin{tabular}{|c|c|}
\hline Methods and techniques used during the stages & $\begin{array}{c}\text { Values of world art } \\
\text { culture }\end{array}$ \\
\hline $\begin{array}{l}\text { The first stage ( } 2-3 \text { months.) } \\
\text { 1. Working with muscular armor, on the basis of } \\
\text { vegetotherapy (V. Reich, A. Lowen, M. Feldenkreis, A. } \\
\text { Baskakov, G. Timoshenko) } \\
\text { 2. Sharing at the beginning and at the end of each class. } \\
\text { 3. The development of authenticity based on the } \\
\text { improvisation using the set characteristics (smooth - long, } \\
\text { soft - short, pulsation, staccato) } \\
\text { 4. Vedic stretching. } \\
\text { 5. The use of bodily metaphor and its analysis. } \\
\text { 6. Basic skills of dance steps (working with the feet, } \\
\text { grounding, sense of self-support) }\end{array}$ & $\begin{array}{l}\text { 1. Popular modern } \\
\text { music; } \\
\text { 2. World music; } \\
\text { 3. "New Age" music; } \\
\text { 4.Dance music (waltz, } \\
\text { Argentine tango, } \\
\text { Rumba); } \\
\text { 5. Classical Jazz, Blues. }\end{array}$ \\
\hline $\begin{array}{l}\text { The second stage ( } 3-4 \text { months.) } \\
\text { 1. Increasing the complexity of the workout by introducing } \\
\text { a more complex control and working on exercises ("Star", } \\
\text { "Red Ball", choreographic placing of the feet, body, } \\
\text { posture) } \\
\text { 2. Increasing the complexity of the figurative elements } \\
\text { of the authentic dance ("Smoke", "Positive aggression", } \\
\text { "Skeleton dance", "Muscle tension dance", "Breath dance", } \\
\text { female and male dance, "Form", "Body geometry", "Vice } \\
\text { versa dance"...) } \\
\text { 3. Spontaneous expressive dance without reliance on the } \\
\text { task. True authenticity. } \\
\text { 4. The basics of contact improvisation. (Work in a pair } \\
\text { and study of elementary steps of ballroom dancing, dance } \\
\text { "dialogue", elementary support) } \\
\text { 5. Vedic paired stretching. }\end{array}$ & $\begin{array}{l}\text { 1. Popular modern, } \\
\text { Ethnic, } \\
\text { «New Age». Dance } \\
\text { music (waltz, Argentine } \\
\text { tango, Rumba); } \\
\text { Classical jazz, Blues. } \\
\text { 2. Classical music } \\
\text { (Viennese classicism, } \\
\text { great romantics, } \\
\text { Impressionists) } \\
\text { 3. Joint viewing of } \\
\text { video films, their } \\
\text { discussion and } \\
\text { rendering of new } \\
\text { images by means of } \\
\text { expressive plastic } \\
\text { with the fixation of } \\
\text { psychological state. }\end{array}$ \\
\hline $\begin{array}{l}\text { The third stage ( } 3-5 \text { months.) } \\
\text { 1. Study of psychological problems on an individual basis } \\
\text { on request; } \\
\text { 2. Creative tasks on the transformation of the original } \\
\text { image given by the psychologist by means of plastic } \\
\text { drama; } \\
\text { 3. The study of new forms and styles of movements, the } \\
\text { location of the body in space, choreographic sketches; } \\
\text { 4. Improved methods of contact improvisation, supports } \\
\text { become spontaneous and more complicated; if necessary, } \\
\text { diagnostic control of interaction is provided; } \\
\text { 5. Creative tasks for the group as a whole, studies, group } \\
\text { cohesion exercises }\end{array}$ & $\begin{array}{l}\text { 1.Music of various } \\
\text { styles, from Mozart to } \\
\text { Led Zeppelin; } \\
\text { 2. World art culture, } \\
\text { historical review with } \\
\text { «full immersion»- } \\
\text { using masterpieces of } \\
\text { art and music, studying } \\
\text { the world view and } \\
\text { style, producing } \\
\text { costumes. }\end{array}$ \\
\hline
\end{tabular}




\begin{tabular}{|l|l|}
\hline \multicolumn{1}{|c|}{ Methods and techniques used during the stages } & \multicolumn{1}{|c|}{$\begin{array}{c}\text { Values of world art } \\
\text { culture }\end{array}$} \\
\hline The fourth stage (5-7 months.) & $\begin{array}{l}\text { 1. Selection of music } \\
\text { with participation of all } \\
\text { group members; } \\
\text { drama: pantomimes, choreography, expressive authentic } \\
\text { forms of bodily expression; }\end{array}$ \\
$\begin{array}{l}\text { 2. Discussion of the theme of theatrical performances, } \\
\text { roles, storyline; }\end{array}$ & $\begin{array}{l}\text { 2. Viewing of theatrical } \\
\text { productions and movies } \\
\text { with discussion of } \\
\text { the "Homeans of actor's } \\
\text { the characters' psychology; }\end{array}$ \\
$\begin{array}{l}\text { 4. Rehearsal process (staging, work on bodily and } \\
\text { psychological difficulties, special attention to the moment } \\
\text { of transformation of the characters) }\end{array}$ & $\begin{array}{l}\text { 3. Selection and } \\
\text { discussion of scenery } \\
\text { and costumes. }\end{array}$ \\
5. First night performance. & \\
\hline
\end{tabular}

The control experiment allowed us to reveal the positive dynamics of psychological and emotional state of students participating in the dance movement therapy training. The most pronounced positive dynamics was observed in relation to: dissatisfaction with one's own way of life in general $(81.25 \% / 29.16 \%)$ and unsatisfied need for creative selfexpression (85.41\%/30.20\%). The percentage of respondents' indications of communicative and emotional-volitional problems in the questionnaire decreased significantly ( $\mathrm{p}<0.01$ ). The Cattell questionnaire showed that the indicators of affectation, sensitivity and hyperthymia were somewhat lower than before, thus indicating a decrease in emotional tension, anxiety and harmonization of background mood. The dynamics in both the control and the experimental group was not statistically significant (Student's t-test).

Campimetry data reveal the following dynamics of states of the respondents in the experimental group. The proportion of subjects with the maximum threshold in red (depressive state) slightly decreased from $22.91 \%$ to $19.79 \%$ ); with the maximum threshold in green (optimal state) - increased from $61.47 \%$ to $78.13 \%$; with the maximum threshold in blue (alarm state) significantly decreased $15.62 \% / 2.08 \%$, which allows us to conclude that changes in the states of training participants are mainly associated with overcoming anxiety states $\left(\chi^{2}=16.67, \mathrm{p}<0.001\right)$. Indicators of depression obtained by campimetry in the control experiment remained almost at the starting level, despite the positive dynamics of emotional and functional states.

In the control group, positive changes were insignificant. There were no valid variations in the dynamics of the subjective assessment of psychological problems by the control group respondents; dynamics indicators of the personal profile (16 PF) among the respondents in the control group were statistically insignificant, although there was a tendency 
toward mood background harmonization; according to the campimetry test, the changes in the state of the control group respondents were insignificant $\left(\chi^{2}=3.54, \mathrm{p}>0.05\right)$.

\section{Conclusions}

Thus, the study of the dynamics of psychological and emotional states of the dance-movement therapy training group participants has revealed a positive dynamics of their changes at the psychological and physiological level.

The combination of spontaneous and cultural movement based on the artistic image and words optimizes the psycho-emotional state of students through creative self-expression in the process of awareness and expressivemotor study of psychological problems of adolescence, overcoming selfdissatisfaction through positive motor and physical experience of social acceptance.

The data of the control experiment showed statistically significant dynamics of the indicators of psychological and emotional states $(\mathrm{p}<0.05)$. At the same time, the dynamics of anxiety was statistically significant, while the level of depression decreased to the trend level. The percentage of respondents' indications of communicative and emotionalvolitional problems in the questionnaire decreased statistically significantly $(\mathrm{p}<0.01)$. At the trend level, there was a decrease of affectation, sensitivity and hyperthymia among the respondents.

According to the results of the control experiment, the psychological and emotional states of the students in the training group of dance movement therapy were optimized, they became more calm, harmonious and functional.

\section{References}

Bakhchina A. V., Koroleva M. E., Polevaya S. A. (2015) Methods for the measurement of primary cognitive functions and sensorimotor coordination. Practicum. Nizhny Novgorod. 45 p.

Blanco, J. R., Rivera, N. E., Gonzalez, J. B., Rodriguez-Villalobos, J. M. (2015) A Gender Study on Mexican College Students' Body-Image Perception. American Journal of Applied Psychology. Vol. 4, No. 6, pp. 166-169.

Daniali, S., Azadbakht, L. \& Mostafavi F. (2013). Relationship between body satisfaction with self esteem and unhealthy body weight management. J Educ Health Promot, 2013(2), 29.

Earhart, G. M. (2009). Dance as therapy for individuals with Parkinson disease. European Journal of Physical and Rehabilitation Medicine. 45 (2): 231-8. PMC 2780534 . PMID 19532110. 
Gutko, A. V., Kuzminykh, L. N., Suvorova, O. V. (2018). Possibilities for a Positive Change in the Body Image of Students in Dance-Motor Training // The Fifth International Luria Memorial Congress «Lurian Approach in International Psychological Science» 2018. - pp. 397-407.

Hanna, J. (2007). The Power of Dance: Health and Healing. The Journal of Alternative and Complementary Medicine. 1 (4): 323-331. doi:10.1089/acm.1995.1.323. PMID 9395627.

Holmqvist Gattario, K. (2013). Body Image in Adolescence: Through the Lenses of Culture, Gender, and Positive Psychology. Department of Psychology, University of Gothenburg, Sweden.

Juliane, S., Cherkin, D., Steuten, L., Sherman, K., Vrijhoef, H. (2011). A Systematic Review of the Evidence for the Effectiveness of Dance Therapy. Alternative Therapies in Health and Medicine. 17 (3): 50-9. PMID 22164813.

Karkou, V., Meekums, B. (2017). Dance movement therapy for dementia. The Cochrane Database of Systematic Reviews. 2: CD011022. doi:10.1002/14651858.CD011022.pub2. ISSN 1469-493X. PMID 28155990.

Levy, F. J. (1988) Dance Movement Therapy: A Healing Art. Reston, VA: The American Alliance for Health, Physical Education, Recreation, and Dance, 1988.

Lowen, A. (2002). Depression and body. - M.: Eksmo-Press. 2002.

Newton, J. H. (2015) Body Image: Impact on Academic Self-Efficacy in Adolescents Alaina NesbiJ, M.S Ed.S. \& Ph.D., NCSP University of Wisconsin - La Crosse.

Pallaro, P. (2007). Authentic Movement: Moving the Body, Moving the Self, Being Moved: A Collection of Essays - Volume Two. London: Jessica Kingsley Publishers. p. 33. ISBN 1846425867.

Polevaya, S. A. (2009) Integration of endogenous factors into the system for exteroceptive signals processing - the author's abstract for the D.Sc. (Biology) dissertation. Pushchino. $51 \mathrm{p}$.

Polevaya, S. A., C. A., Runova, E. V., Nekrasova, M. M., Fedotova, I. V., Kovalchuk, A. V., Bahchina, A. V., Chesalov, I. S., Parin, S. B. (2012). Telemetry and information technologies in diagnostics of functional state of sportsmen / / Modern technologies in medicine. - Nizhny Novgorod: Publishing house "Nizhny Novgorod state medical Academy”, № 4. - pp. 94-98.

Pop, C. (2016). Self-Esteem and body image perception in a sample of university students. Eurasian Journal of Educational Research, 64, 31-44 http://dx.doi. org/10.14689/ejer.2016.64.2

Raich, V. (1999). Analysis of the individual. - M.: “Juventus”. - 333 p.

Rohricht, F. (2009). Body oriented psychotherapy. The state of the art in empirical research and evidence-based practice: A clinical perspective // Body, Movement and Dance in Psychotherapy. - Vol. 4. - № 2. - pp. 135-156.

Shilder, P. (1978). The image and appearance of the human body. - New York: International Universities Press, 1978.

Stromkova, E. G., Parin, S. B., Polevaya, S. A. (2004) Influence of stress on the differential thresholds of color perception. Vestnik of the Lobachevsky State University of Nizhny Novgorod/ Nizhny Novgorod, UNN Publishing House. - pp. 46-56.

Wright, T. L., (2012) Body Image and Healthy Lifestyle Behavior Among University Students. UNF Theses and Dissertations. 402. http://digitalcommons.unf.edu/etd/402 